\title{
Analysis of the tool life of coated hob milling tools for gear cutting of cylindrical gear
}

\author{
Sandra Sovilj-Nikić ${ }^{1,}$, Bogdan Sovilj ${ }^{2}$, Gyula Varga $^{3}$, Nicolae Ungureanu ${ }^{4}$ and Vladimir Blanuša ${ }^{5}$ \\ ${ }^{1}$ Iritel a.d. Beograd, 11000 Belgrade, Serbia \\ ${ }^{2}$ University of Novi Sad, Faculty of Technical Sciences, 21000 Novi Sad, Serbia \\ ${ }^{3}$ University of Miskolc, Faculty of Mechanical Engineering and Informatics, 3515Miskolc, Hungary \\ ${ }^{4}$ North University of Baia Mare, Engineering Faculty, 430311 Baia Mare, Romania \\ ${ }^{5}$ High Technical School of Professional Studies, 21000 Novi Sad, Serbia
}

\begin{abstract}
The improvement of the gear cutting process by hob milling is also significant for the producers of gears as well as for the producers of hob milling tools. Due to the complexity of the process, the high values of the gears, and in particular the hob milling tool, the research of the bases for optimizing the process of gear cutting by hob milling requires significant financial resources and significant efforts of the researchers. In the modern production of gears there is a continuous demand for increasing the economy. In the gear cutting process improvements of the production equipment and materials for the cutting elements of the hob milling tools are necessary. In this paper an analysis of the tool life of coated hob milling tools for gear cutting of cylindrical gears is given. The experimental results have shown that the hob milling tools with inserted combs coated with TiAlN outperform the hob milling tools with inserted combs coated with TiN. They have higher resistance of $60.6 \%$.
\end{abstract}

\section{Introduction}

The occurrence of the power transmitter and movement dates back to ancient times. In China, Mesopotamia and Egypt, parts and assemblies of irrigation devices with toothed portable elements have been found, which according to the kinematic principle are still used today. In addition to agriculture, such devices have been developed for war and civil engineering purposes [1].

Modern gear cutting of cylindrical gears is most often performed by relative rolling methods, i.e. hob milling and hob planning. Thanks to the high productivity of the process, the hob milling has the widest application in the gear cutting of cylindrical gears. The process of hob milling of cylindrical gear serration is one of the most important operations in the technological process of machining, since the productivity, the final geometric accuracy and the quality of serration surface depend on the machining methods and the applied tools [2, 3].

Tribo-mechanical power transfer systems, known in the engineering as mechanical transmissions, are used to transmit energy of mechanical motion at a distance, as well as to modify its parameters. At the same time, they transfer revolving motion. The general purpose of the transmission is firmly associated with the performance of elementary functions, among which the most characteristic are: energy distribution, reduction or increase of speed, change of motion type, speed control, start, stop, direction change, etc. Functionality of mechanical transmission is based on a specific triboelement form and the corresponding law of meshing the contact surfaces. This group of transmissions includes: transmission gears, chain transmissions, timing belt drives, cardan shafts, variator transmissions and all of them found their application in modern technology.

\section{Gear cutting and materials for manufacturing of hob milling tools}

The problem of the production of gears is analyzed in science and practice in various ways, identifying it once as an element of the machine and another time as a part of the production, that is, a final product. The basic types of serration, the basic types of tools and the basic methods of gear cutting are shown in the Figure $1[3,4,5,6]$.

Designed and properly manufactured gears are key components in most complex systems. Gears with involute teeth are among the most important components of efficient modern transmission techniques, in accordance with relevant legislation on pollution and energy saving. Figure 2 [6] shows how to get involute. In the hob milling process, the teeth and hollows between teeth are formed by removing the material from the workpiece. Problems that arise in the process of material removal are due to the presence of tribological processes on the contact surfaces of the elements of tribomechanical system.

\footnotetext{
* Corresponding author: sandrasn@eunet.rs
} 


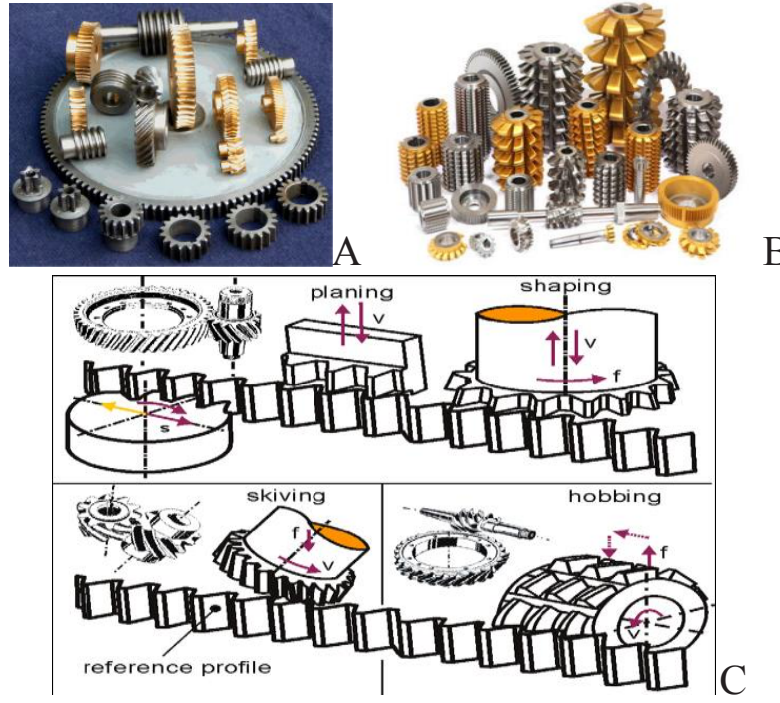

Fig. 1. Basic types of gears, hob milling tools and gear cutting methods

In the Figure 1c $[3,6]$ examples of tribo-mechanical systems with basic tribo-mechanical elements and basic methods of gear cutting are given.

A fundamental knowledge of the process of producing transmission gears is crucial to oppose the demands for continuous improvement in a globalized market. Related development is continually involved in the development and production of machine tools and tools for gear cutting.

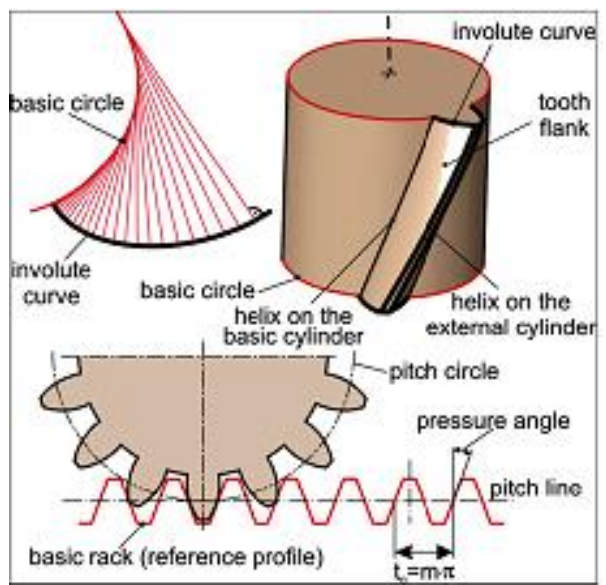

Fig. 2. Involute derivation

Manufacturers of involute cylindrical gears during their production process, regardless of their size, from a few millimeters to several meters (Figure 3 [6]), face common technological problems. The predictability of machining parameters, such as geometry and chip flow, tool wear, etc., with regard to work-piece, tool and machining data is of great interest for research and industry. The changeable chip formation during the manufacturing process of serration of cylindrical gears causes different wear laws.

Production operations and methods in mass production depend on various parameters such as the cost of machining, production philosophy, practical experience, etc. A common strategy is to achieve the highest possible accuracy during roughing and to perform thermal treatment with the necessary tolerance to completely avoid finishing [3].

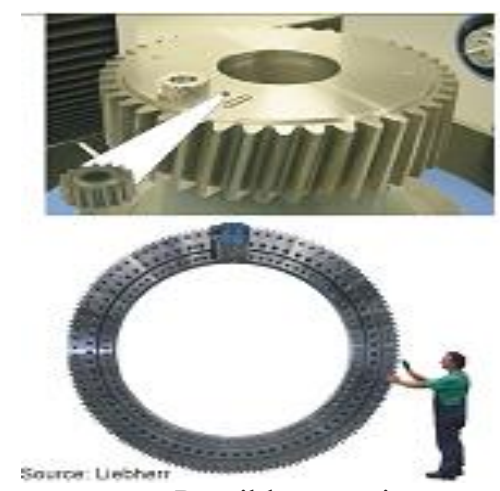

Fig. 3. Possible gear sizes

Hob milling is a multi parametric and complex method for gear cutting of cylindrical gears. Hob milling is an efficient machining process for the production of serration of high quality cylindrical gears. This process is related to complicated kinematics, the formation and the flow of chip, as well as to the hard-to-describe tool wear mechanisms.

The hob milling process is one of the most important links in the chain of gear machining, having in mind that the productivity, the final geometric accuracy and the quality of the serration depend to a great extent on the hob milling process.

Gear cutting operations most often represent a bottleneck in the production of cylindrical gears, especially in higher types of production. Therefore, the necessity of research and development of optimal tool constructions, as well as research of the optimal conditions of these processes, especially hob milling, is obvious.

The optimization of the production conditions for the gear cutting of the cylindrical gears depends to a large extent on the correctness of the selection and maintenance of the hob milling tool, as well as on the selection of the appropriate cutting regimes.

The modern technical development of the production of cylindrical gears is directed in two basic directions: increase the productivity of the appropriate process and gear cutting while improving the quality of the machined serration. Achieving these, mostly opposite, demands is a very complex task.

The productivity and cost-effectiveness of the hob milling is determined by: the characteristics of the hob milling machine, the construction characteristics of the hob milling tool and the material of the cutting edge [3]. The enhancement of the hob milling of serration of cylindrical gears can be achieved by increasing the productivity and increasing the quality of the serration (Figure 4 [2,3]).

In industrial countries today, losses in billions of Euros are generated through wear and corrosion when manufacturing and using mechanical gears. For this reason, the design of hob milling tools, that will provide minimal losses of this type, is of great importance expressed through the construction and cutting geometry of the hob milling tool, and also through the selection of the optimal tool material. 


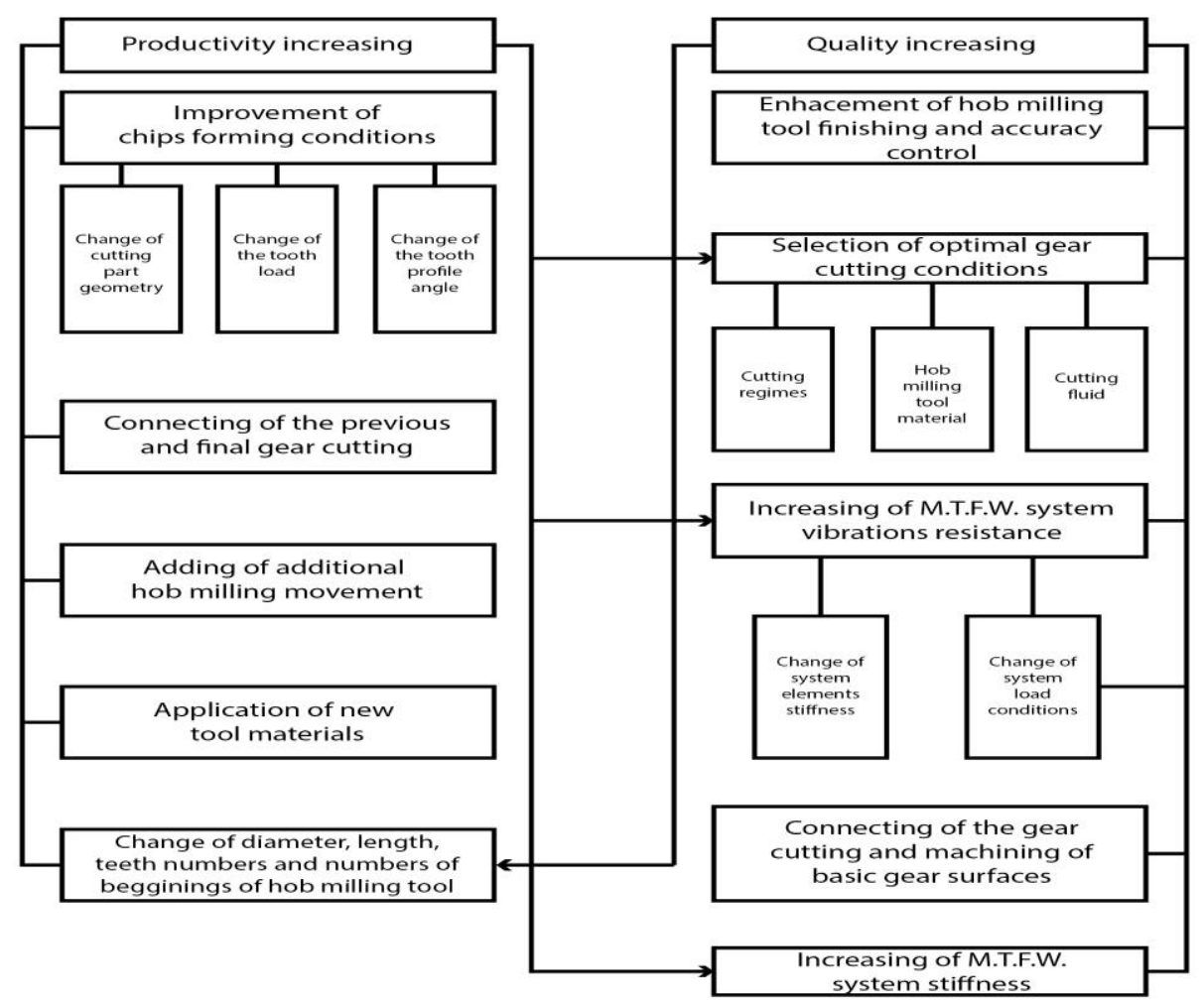

Fig. 4. Enhancement directions of hob milling of cylindrical gear serration

The influence of the structure and microstructure of the materials and technological processes of manufacture of blank and work-piece and the properties and behavior of the material, as well as their interaction are given in $[7,8]$. Improving and finding more perfect materials has played the most important role in the development of gear cutting tools of cylindrical gears by hob milling [3]. Hob milling tools are made of high-speed steel, cementedcarbide, sintered alloys, etc.

The development of new and improvement of the existing materials for the production of hob milling tools in order to minimize the total cost of gear cutting and retain the same quality of gear cutting is of great importance in view of the current economic situation. The steadily growing demands placed on the hob milling tools require the continuous development and finding of new methods for making combined materials. Significant progress has been made in that field in the last fifteen years. A large number of hard materials coating methods have been developed in order to protect against the wear of the hob milling tools, but due to insufficient knowledge and experience, they slowly find application in the industry $[3,6]$.

The process of the gear cutting by hob milling is characterized by different thicknesses and lengths of the chips, and the materials from which the cutting edge of hob milling tools are made should have significant tenacity and hardness. Based on the previous significant attention is paid to the strengthening of the hob milling tool by applying a permanent layer to the working surfaces of the hob milling tool. The application of coated hob milling tools is conditioned by their high efficiency. Until now there is no correlation between the strength of the hob milling tool and the properties of the coating layer, and the issues of optimizing the properties of the complex layer and the tool base remain open. There are also difficulties in the industrial application of progressive surface reinforcement technology and the rational application of a reinforced hob milling tool $[3,6,9,10]$.

The tendency of the material development for the hob milling tools and the technology of their surface reinforcement are conditioned by the need directed towards improving the physical and mechanical properties of the material for the hob milling tools, among which strength, thermostability, resistance and brittleness have long been considered to be important, while other properties are considered to be less important. Ignoring the importance of certain properties of the hob milling tool materials is one of the main reasons for the lack of understanding of the main functions of the layer's stability on the hob milling tool.

There are more than one hundred different methods of surface coating of metals and alloys, by which it is possible to increase the efficiency of the tool to a certain extent. An overview of basic techniques and surface engineering (surface modification and application of a layer) is shown in Figure $5[3,11,12]$. In Figure $6[3,12]$, coating techniques based on the physical state of the applied material are given. The surface coating technique is perfected by a rapid rhythm, which greatly contributes to the development of theoretical concepts in the field of surface resistance of materials. 


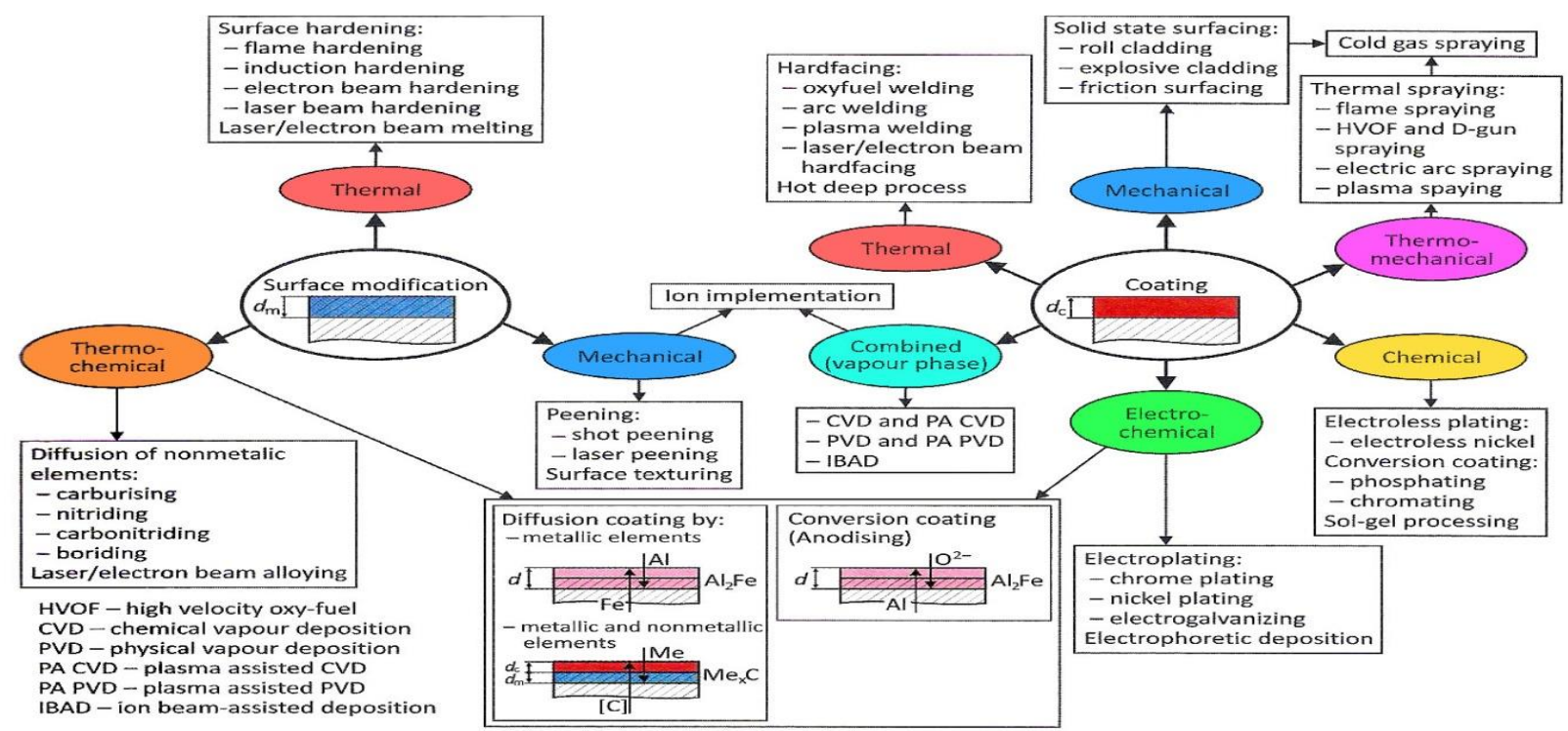

Fig. 5. Overview of main surface engineering(surface modification and coating deposition)techniques

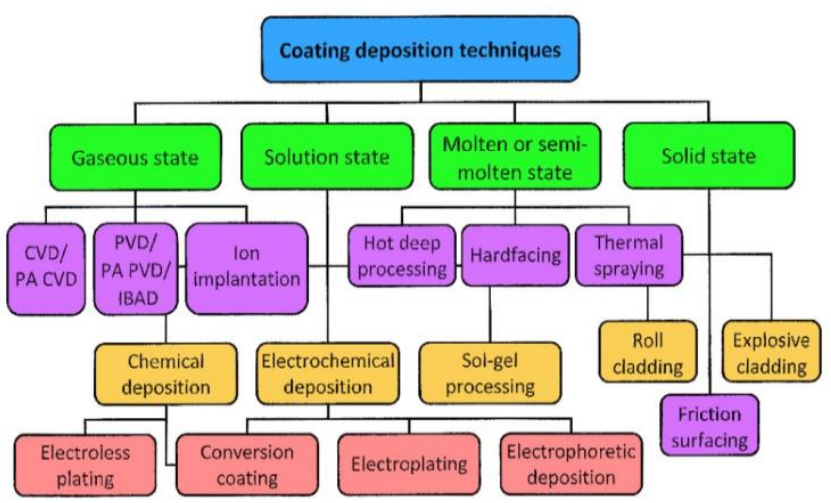

Fig. 6. Overview of main surface engineering (surface modification and coating deposition) techniques

Today, high-speed steel hob milling tools continue to be used primarily for gear cutting in the automotive industry, especially in the production of truck changers. The further evolution of metallurgy of powdered highspeed steel in combination with the application of PVD layers has contributed to this application and the development of high-speed steel. Coated hob milling tools made of high-speed steels are also used for dry gear cutting of cylindrical gears.

Cemented-carbide hob milling tools are also used in gear cutting of cylindrical gears. These tools have a high wear resistance. With these tools, there is the possibility of increasing the cutting speed in order to increase productivity and reduce production costs. Mechanisms affecting the reliability of the process of gear cutting by hob milling tools of cemented-carbide are caused by a stochastic occurrence of a built-up-edge on the cutting edge and a deterioration of the cutting ability after the sharpening of the hob milling tools $[3,6]$.

Hob milling tools can also be made from sintered alloy. In the comparison with conventional cementedcarbide based on tungsten carbide, they have shown greater hardness and wear resistance, including high blade stability. This ensures the invariability of the form and dimensions of smaller tool cutting edge and better machined surface of the work-piece. Good cutting edge stability allows the use of this material for hob milling tools with smaller module. The rounded cutting edge of hob milling tools from the sintered alloy to prevent damage does not produce better results. The reason for this is the fact that the sintered alloy cutting edges have already increased stability. The cracks that occur on the tools of this material and represent one of the wear criteria are not the result of an unstable cutting edge and do not arise accidentally. They are largely the result of damage of the structure. The rounded cutting edge results in an increase in the cutting force, which leads to occasional damage of the face surface and decrease tool life.

The productivity of the hob milling of cylindrical gears serration has not been able to increase until now using sintered alloys instead of cemented-carbide. Cemented-carbide hob milling tools have greater tool life than sintered alloy tools. Based on the aforementioned, it can be concluded that today, sintered alloys cannot be economically applied for hob milling tools. As previously mentioned, the design and the material of the hob milling tool are also important. Hence, an attention will be paid to this in the experimental part of this paper.

\section{Material and method}

In the framework of the research on project entitled The Modeling and Optimization of the Hob Milling Process [3], one part is dedicated to hob milling tools. In the paper [13], the advantages of the hob milling tools with inserted cutting elements-combs in relation to the integral hob milling tools are highlighted. The experimental results have shown that the hob milling tools with inserted coated combs have a greater resistance of $27.28 \%$ in comparison to the hob milling tools with inserted uncoated combs [8]. This paper presents only a part of experimental research. The experiments were carried out in several positions with hob milling tools with inserted coated combs. The combs are coated with TiN and TiAlN. The work-piece material 
is $20 \mathrm{MnCr} 5$. The serration of straight cylindrical gear was machined. Its characteristics are: the module $\mathrm{m}=4.75$ $\mathrm{mm}$, the number of gear teeth $z_{2}=39$, the angle of the contact line $\alpha=20^{\circ}$, the angularity of the gear tooth $\beta=0^{\circ}$, the width of the serration $b=66 \mathrm{~mm}$, the diameter of the work-piece $\Phi 194.75$. Tools with the diameter $\mathrm{d}_{\mathrm{ht}}=145 \mathrm{~mm}$, length $\mathrm{l}_{\mathrm{ht}}=180 \mathrm{~mm}$, module $\mathrm{m}$ $=4.75 \mathrm{~mm}$ with one beginning, 12 teeth at one comb and 14 teeth per circumference were used on the hob milling tool. In the experiments, the cutting speed $\mathrm{v}_{\mathrm{c}}=101.94 \mathrm{~m} / \mathrm{min}, \mathrm{n}=224 \mathrm{r} / \mathrm{mm}$ and the feed $\mathrm{f}_{\mathrm{a}}=2 \mathrm{~mm} / \mathrm{r}$ were used, which were determined in the previous researches as optimal. The hob milling tool is moving for $f_{t}=1.25 \mathrm{~mm}$ after gear cutting on one workpiece in order to equalize the wear of as many teeth as possible on the hob milling tool. The body and rings of hob milling tool are made of $42 \mathrm{CrMo} 4$, and the comb of HS6-5-2-5. Coating of the combs was done with TiN and TiAlN. Measuring and checking of the hob milling tools and gears were carried out on a special measuring machine KLINGEBERG. Monitoring and measurement of wear were carried out using a special magnifier and tool microscope manufactured by KARL ZEISS. The gear cutting was carried out by (up) conventional milling.

\section{Results and discussion}

In tribological processes, the very small mass of the tool material and the large mass of the material of the workpiece are involved in the machining of serration of the gear. The consequences of the development of tribological processes in the zones of contact are the friction and wear of the cutting elements of hob milling tools [14].

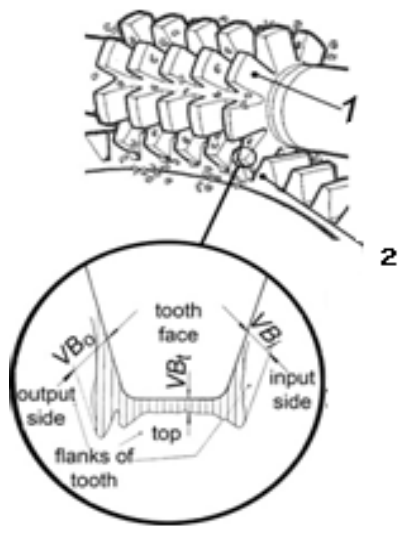

Fig. 7. Tribo-mechanical system for gear cutting

The wearing process takes place on the teeth in contact with the work-piece. The hob milling tool and work-piece make a tribo-mechanical system (Figure 7 [3]). The Figure shows the detail of wear on one tooth of the hob milling tool. The primary processes of wear are the most important. In the experiments shown in this paper, the flank wear on the back surfaces of the hob milling tool teeth are the primary wear zone. The back surface of the teeth of the hob milling tools wears on the input lateral back surface cutting edge, the tip back surface cutting edge and the output lateral back surface cutting edge. The development of the wear process on one tooth of the hob milling tool is given in the Figure 8. The Figure shows the wear on all three back surfaces. The wearing of the output lateral back surface of cutting edge $\mathrm{VB}_{\mathrm{O}}=0.7 \mathrm{~mm}$ in roughing has been adopted as a wear criterion. At the cutting speed of $\mathrm{v}_{\mathrm{c}}=101.94 \mathrm{~m} / \mathrm{min}, \mathrm{n}=224 \mathrm{r} / \mathrm{min}$ and axial feed $f_{a}=2 \mathrm{~mm} / \mathrm{r}$, the hob milling tool with inserted TiN coated combs made of high speed steel manufactured by powder metallurgy had a tool life $\mathrm{L}=$ $2178 \mathrm{~mm}$ on machined serration of straight cylindrical gear (Figure 8a).

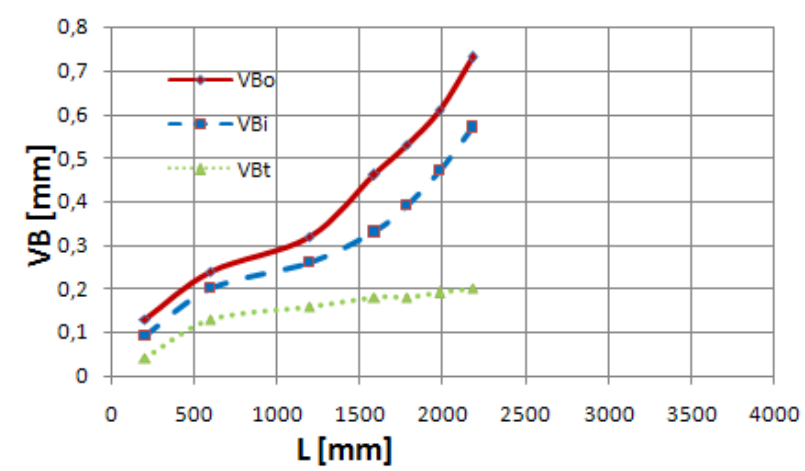

A

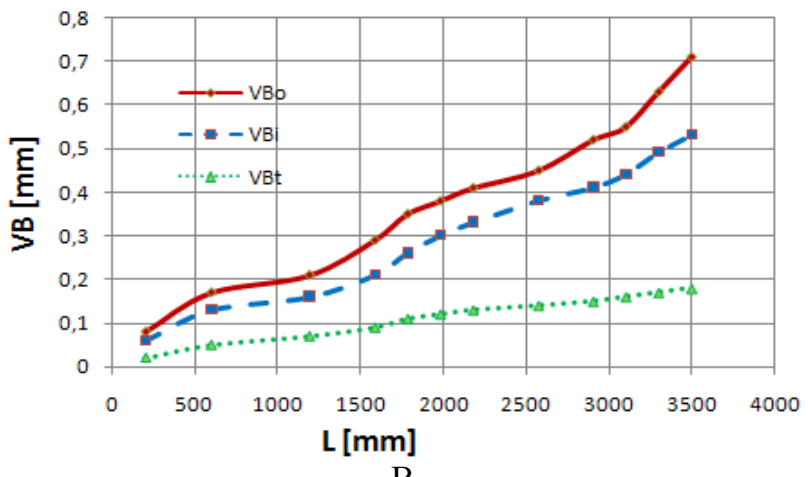

B

Fig. 8. The development of the wear process on hob milling tools coated with TiN and TiAlN

The development of the wear process on one tooth of the hob milling tool with inserted combs of high speed steel manufactured by powder metallurgy and combs coated with TiAlN is shown in the Figure 8 b. The tool life of this tool with the same cutting regimes and the same wear criterion was $\mathrm{L}=3498 \mathrm{~mm}$ of machined serration of straight cylindrical gears.

Comparative studies of hob milling tools with inserted TiN coated combs made of high speed steel, manufactured by powder metallurgy and hob milling tools with inserted combs of the same material and coated with TiALN were performed in real production conditions. These experimental researches once again confirmed that there is a concentrated wear on the cutting elements of the hob milling tools when gear cutting of straight cylindrical gears. The morphology of the flank wear is characterized by the appearance of most commonly two grooves on the output lateral back surface and one groove at the input 
lateral side back surface. The grooves in the cutting elements of the hob milling tool are located in the transition areas of the tip back surface into the output and input lateral back surfaces.

The experimental researches have shown that the hob milling tools with inserted TiAlN coated combs have a higher resistance of $60.6 \%$ compared to the hob milling tools with inserted TiN coated combs. Previous and these studies have shown that the design, that is, the construction of the hob milling tools and the coating with TiAlN, have great significance for increasing the tool life of the hob milling tools and the quality of the machined serration. It is important to note that the operating modes were the same for all the hob milling tools used in experimental research. Based on the knowledge in the available literature and own research with tools coated with TiAlN, it is possible to apply larger cutting regimes and thus achieve even more techno-economic effects. In further research, comparative testing and application of hob milling tools coated with two or more layers of different manufacturers should be carried out as well as their more rational application. It is necessary to research the technological and economical characteristics of hob milling tools with several beginnings and a new construction of hob milling tools.

\section{Conclusion}

On the basis of theoretical and experimental researches, the necessity for further researching the hob milling process of the serration of straight cylindrical gear is obvious.

The experimental results have shown that the hob milling tools with inserted combs coated with TiAlN have a greater resistance of $60.6 \%$ in comparison to the hob milling tools with inserted combs coated with TiN.

The effects of the application of hob milling tools coated with TiAlN would be considerably better if cutting speeds greater than $180 \mathrm{~m} / \mathrm{min}$ were applied.

\section{References}

[1] M. Opalić, Mechanical transmissions and motion (Prijenosnici snage i gibanja), Sveučilište u Zagrebu, FSB, Zagreb, Croatia (1998)

[2] I. Sovilj-Nikić, Application of genetic algorithm in optimization of geometric parameters of hob milling tool (Primena genetskog algoritma u optimizaciji geometrijskih parametara odvalnog glodala), Fakultet tehničkih nauka, Novi Sad, Serbia, Master Thesis (2007)

[3] I. Sovilj-Nikić, Modeling and optimization of hob milling process (Modelovanje i optimizacija procesa odvalnog glodanja), Fakultet tehničkih nauka, Novi Sad, Serbia, Doctoral Thesis (unpublished)
[4] http://w.w.w.indiamart.com

[5] http://w.w.w.ags-industrial.com

[6] K. D. Bouzakis, E. Lili, N. Michalidis, O. Friderikos, Manufacturing of cylindrical gears by generating cutting processes: A critical synthesis of analysis methods, CIRP Ann. 57, 676-696 (2008)

[7] T. Filetin, M. Franz, Đ. Španiček, V. Ivušić, Properties and characteristics of material (Svojstva $i$ karakteristike materijala), Sveučilište u Zagrebu, Fakultet strojarstva i brodogradnje, Croatia (2012)

[8] B. Sovilj , S. Sovilj-Nikić, G. Varga, V. Blanuša, Analysis of the possibility of improving the characteristics of hob milling tools for gear cutting of cylindrical gears, Proceedings of International Scientific Conference KOD 2018, 6-8 June 2018, Novi Sad, Serbia (2018)

[9] K. D. Bouzakis, G. Skoridatis, M. Michalidis, Innovative methods for characterizing coatings mechanical properties, Proceedings of International Conference 'The Coatings 2008', October 2008, Kallithea, Greece (2008)

[10]I. Sovilj-Nikić, S. Sovilj-Nikić, B. Sovil, R. Đokić, Analysis of roughness parameters of the tooth-face of model hob milling tool, Mach. Dsgn 9(3), 99-106 (2017)

[11] M. Stupnišek, B. Matijević, Overview of procedures for modifying and coating of metal (Pregled postupaka modificiranja i prevlačenja metala), Proceedings of International Scientific Conference "Thermal treatment of metal and surface engineering" (Znanstveno stručni skup s međunarodnim učešćem 'Toplinska obradba metala i inženjerstvo površina'), Zagreb, Croatia, Jun 8, 53-62 (2000)

[12] M. Kandeva-Ivanova, A. Vencl, D. Karastoyanov, Advanced Tribological Coatings For Heavy-Duty Applications: Case Studies, Prof. Marin Drinov Publishing House of Bulgarian Academy of Sciences, Bulgaria (2016)

[13]B. Sovilj, A. Popov, D. Ješić, I. Kolev, I. SoviljNikić, Treatment in Tribological Processes of Spur Gear in Modern Agricultural Engineering, Con. Agricul.Eng. 37(3), 305-313 (2011)

[14] I. Sovilj-Nikić, S. Sovilj-Nikić, B. Sovilj, V. Blanuša, Topography of Characteristics Surfaces of Model Hob Milling Tools for Machining of Gear Serration, Proceedings of International Scientific Conference IRMES 2017, 7-9 September 2017, Trebinje, Bosnia and Herzegovina, 241-246 (2017)

\section{Acknowledgments}

The research was funded by the Ministry of Education, Science and Technological Development of the Republic of Serbia, within the projects TR 35015 and III 43008, and it is also the result of the cooperation within CEEPUS project CIII- RO-0058-07-1415. 